\title{
Is it time to expand the indications for pulmonary embolectomy?
}

\author{
Juan A. Crestanello, MD
}

\author{
From the Wexner Medical Center, The Ohio State University, Columbus, Ohio. \\ Disclosures: Author has nothing to disclose with regard to commercial support. \\ Received for publication Oct 8, 2017; accepted for publication Oct 13, 2017; available ahead of print Nov 9, 2017. \\ Address for reprints: Juan A. Crestanello, MD, Division of Cardiac Surgery, Wexner Medical Center, The Ohio \\ State University, N-820 Doan Hall, 410 West 10th Ave, Columbus, OH 43210 (E-mail: juan.crestanello@ \\ osumc.edu). \\ J Thorac Cardiovasc Surg 2018;155:1093-4 \\ 0022-5223/\$36.00 \\ Copyright (C) 2017 by The American Association for Thoracic Surgery \\ https://doi.org/10.1016/j.jtcvs.2017.10.045
}

The development of treatments for pulmonary embolism (PE) played a key role in the advancement of cardiac surgery. In the early 1900 s, Trendelenburg ${ }^{1}$ recognized that after a PE, there was a window of opportunity before death when a "trial of operative treatment could be made." In 1908, he attempted the first pulmonary embolectomy, resulting in the death of the patient. ${ }^{1}$ It was not until 1924 that his disciple, Kirschner, ${ }^{2}$ performed the first successful embolectomy. The outcomes after surgical embolectomy remained poor. ${ }^{1}$ Eighty years ago, John H. Gibbon ${ }^{3}$ had a very negative outlook on the outcomes of surgery for PE: "Approximately one hundred and forty-two Trendelenburg operations for massive PE have been reported, and only nine of the patients operated on have left the hospital as cured." These poor outcomes were the main impetus for him to work on the development of the cardiopulmonary bypass machine. ${ }^{3}$ In the early 1960s, Sharp ${ }^{4}$ and Cooley and colleagues ${ }^{5}$ were the first to perform embolectomies using cardiopulmonary bypass support. From 1962 to early 2000, surgery was reserved for patients in extremis or cardiac arrest as the last attempt to save their lives. ${ }^{6}$ The outcomes were poor with an operative mortality in excess of $30 \%{ }^{6}$ Then in the early 2000s, 2 events led to a resurgence of pulmonary embolectomy. One was the advent of computed tomography pulmonary angiography, which allowed for an accurate and prompt diagnosis. Second was the report from the Brigham and Women's Hospital that a multidisciplinary and systematic approach to the management of massive and submassive PE characterized by early diagnosis and early surgical intervention can result in greater than $93 \%$ operative survival. ${ }^{7,8}$

In this issue of the Journal, Lee and colleagues ${ }^{9}$ report on the use and outcomes of pulmonary embolectomy and thrombolysis in the state of New York from 1993 to 2013. This article sheds light on the real-life experience with pulmonary embolectomy and thrombolysis in the community. There are several remarkable findings in this article. The first is that both thrombolysis and pulmonary embolectomy are rarely used. Only $1 \%$ of the patients received

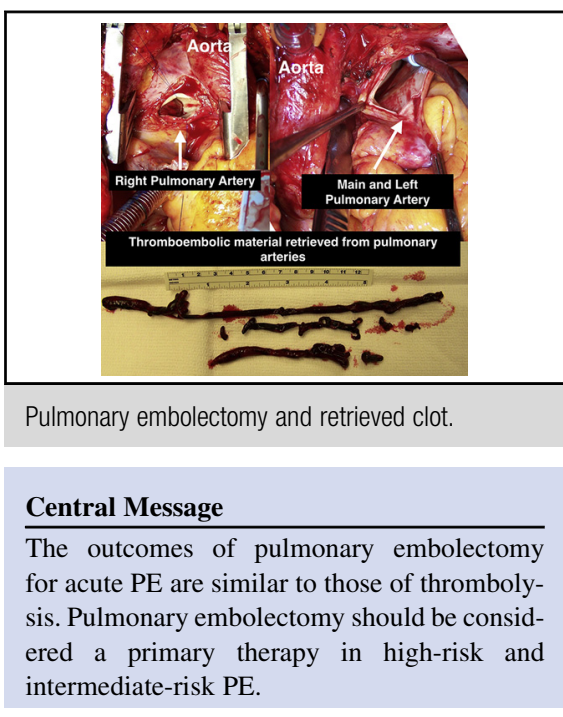

See Article page 1084.

thrombolysis, and $0.14 \%$ of patients received embolectomy. This low rate is remarkably similar to the use rate from the Nationwide Inpatient Sample. ${ }^{10,11}$

Second, the number of pulmonary embolectomies and thrombolysis performed per year started to increase in the early 2000s, likely as result of the increased availability of computed tomography angiography but also from the popularization of the work by Aklog and colleagues ${ }^{7}$ among the surgical community. ${ }^{8}$

Third, the 30-day mortality of surgical embolectomy was strikingly low $(15 \%)$, which is half that reported in the Nationwide Inpatient Sample and approaches the mortality reported by specialized single-center studies. ${ }^{7,8,12}$

Fourth, it is hard to compare the outcomes of embolectomy and thrombolysis given the limitations of the article on identifying the baseline characteristics, degree of hemodynamic compromise, and indications for each treatment. Despite these limitations, there was no difference in 30-day or 5-year mortality between thrombolysis and embolectomy. This is remarkable because it is likely that embolectomy was reserved for the patients with contraindications to thrombolysis or with worse hemodynamics.

Fifth, the outcomes of pulmonary embolectomy were similar regardless of where they were performed. This is an important point that allows for increased patient access to this lifesaving procedure. 
Finally, how do these results affect practice? Neely and colleagues ${ }^{13}$ recently reported on more than 100 patents with massive and submassive PE who had embolectomies with an operative mortality of less then $7 \%$ and good long-term outcomes. The current guidelines reserve the use of surgical embolectomy for patients with high-risk PE (patients in shock or hypotensive) who have contraindications to thrombolysis or as a rescue in those who have failed thrombolysis. ${ }^{14}$ They also recommend embolectomy as a primary or rescue treatment for intermediate-risk PE in patients in whom hemodynamic decompensation seems imminent and the anticipated bleeding risk under systemic thrombolysis is high. ${ }^{14}$ The results of the current study and those of Neely and colleagues ${ }^{13}$ support the expanded use of pulmonary embolectomy as a first line of therapy in highrisk and intermediate-risk PEs.

\section{References}

1. Trendelenburg F. Uber die operative Behandlung der Embolie der Lungenarterie. Arch Klin Chirurg. 1908;86:688-700.

2. Kirschner M. Ein surch die Trendelenburgische operation geither fall von embolie der art pulmonalis. Arch Klin Chirurg. 1924;133:312.

3. Gibbon JH. Artificial maintenance of circulation during experimental occlusion of pulmonary artery. Arch Surg. 1937;34:1109.
4. Sharp EH. Pulmonary embolectomy: successful removal of a massive pulmonary embolus with the support of cardiopulmonary bypass: case report. Ann Surg. $1962 ; 156: 1$

5. Cooley DA, Beall AC, Alexander JK. Acute massive pulmonary embolism. JAMA. 1961;177:283-6

6. Stein PD, Alnas M, Beemath A, Patel NR. Outcome of pulmonary embolectomy, Am J Cardiol. 2007;99:421-3.

7. Aklog L, Williams CS, Byrne JG, Goldhaber SZ. Acute pulmonary embolectomy: a contemporary approach. Circulation. 2002;105:1416-9.

8. Leacche M, Unic D, Goldhaber SZ, Rawn JD, Aranki SF, Couper GS, et al. Modern surgical treatment of massive pulmonary embolism: results in 47 consecutive patients after rapid diagnosis and aggressive surgical approach. J Thorac Cardiovasc Surg. 2005;129:1018-23.

9. Lee T, Itagaki S, Chiang YP, Egorova NN, Adams DH, Chickwe J. Survival and recurrence after acute pulmonary embolism treated with pulmonary embolectomy or thrombolysis in New York State between 1999-2013. J Thorac Cardiovasc Surg. 2018;155:1084-90.

10. Stein PD, Matta F. Case fatality rate with pulmonary embolectomy for acute pulmonary embolism. Am J Med. 2012;125:471-7.

11. Stein PD, Matta F. Thrombolytic therapy in unstable patients with acute pulmonary embolism: saves lives but underused. Am J Med. 2012;125:465-70. Erratum in: Am J Med. 2012;125:e13.

12. Kilic A, Shah AS, Conte JV, Yuh DD. Nationwide outcomes of surgical embolectomy for acute pulmonary embolism. J Thorac Cardiovasc Surg. 2013;145:373-7.

13. Neely RC, Byrne JG, Gosev I, Cohn LH, Javed Q, Rawn JD, et al. Surgical embolectomy for acute massive and submassive pulmonary embolism in a series of 115 patients. Ann Thorac Surg. 2015;100:1245-52.

14. Konstantinides SV, Torbicki A, Agnelli G, Danchin N, Fitzmaurice D, Galiè N, et al; Task Force for the Diagnosis and Management of Acute Pulmonary Embolism of the European Society of Cardiology (ESC). 2014 ESC guidelines on the diagnosis and management of acute pulmonary embolism. Eur Heart J. 2014;35:3033-69. 3069a3069k. Erratum in: Eur Heart J. 2015;36:2666. Eur Heart J. 2015;36:2642. 